\title{
Role of SOD2 Ala16Val polymorphism in primary brain tumors
}

\author{
AYCA TAȘ ${ }^{1}$, YAVUZ SILIGG $^{2}$, HATICE PINARBAȘI ${ }^{2}$ and MUSTAFA GÜRELIK ${ }^{3}$ \\ ${ }^{1}$ Department of Nutrition and Diet, Faculty of Health Sciences; ${ }^{2}$ Department of Biochemistry, Faculty of Medicine, \\ Sivas Cumhuriyet University, 58140 Sivas; ${ }^{3}$ Clinic of Neurosurgery, Medicana Sivas Hospital, 58050 Sivas, Turkey
}

Received November 13, 2018; Accepted February 4, 2019

DOI: $10.3892 /$ br.2019.1192

\begin{abstract}
The present study aimed to investigate the possible association between the genetic polymorphism of the enzyme superoxide dismutase 2 (SOD2, also known as manganese-dependent SOD), Ala16Val (rs4880), and primary brain tumor risk in the Turkish population. Frequency of the SOD2 gene rs4880 polymorphism was identified in 225 Turkish individuals (120 controls and 105 patients with primary brain tumor) by polymerase chain reaction-restriction fragment length polymorphism. Subject demographics and clinical characteristics were also recorded. The findings were evaluated using logistic regression and $\chi^{2}$ tests. Logistic regression analysis indicated that smoking did not increase the risk for primary brain tumor [odds ratio $(\mathrm{OR})=0.77,95 \%$ confidence interval $\left.(\mathrm{CI})=0.44-1.33, \chi^{2}=0.352, \mathrm{P}=0.860\right]$. Similarly, there was no statistically significant difference in the family history of cancer incidence between the control subjects and the primary brain tumor patients $(\mathrm{OR}=0.81,95 \% \mathrm{CI}=0.39-1.71$, $\left.\chi^{2}=0.340, \mathrm{P}=0.560\right)$. There was no significant association of the histopathological type, genotype/allele frequencies and inheritance models of tumor with the gene variants among the patients with primary brain tumor. In summary, the results of the present study indicated that the Ala16Val polymorphism of the SOD2 gene was not associated with primary brain tumor risk in the Turkish population studied.
\end{abstract}

\section{Introduction}

Cancer is a major public health problem worldwide. Brain and central nervous system tumors refer to a series of rarely-occurring tumors (1) In 2018, it is expected that 23,880 new cases (13,720 males and 10,160 females) of brain and central nervous system tumors were diagnosed and 16,830 (9,490 males and 7,350 females) are expected to have died due to these types of

Correspondence to: Professor Yavuz Siliğ, Department of Biochemistry, Faculty of Medicine, Sivas Cumhuriyet University, 58140 Sivas, Turkey

E-mail: ysilig@cumhuriyet.edu.tr

Key words: primary brain tumors, polymorphism, superoxide dismutase 2, manganese superoxide dismutase, Ala16Val, Turkish population tumor in the United States, accounting for approximately $2 \%$ of all cancers diagnosed nationally $(1,2)$. Data published by the Turkish Health Ministry in 2018 (Turkey United Database, 2011-2015) indicated that approximately 163, 500 new cases of cancer are diagnosed annually, and approximately 450 individuals are diagnosed with cancer daily; furthermore, brain, meningeal and central nervous system tumors in Turkey had a reported prevalence of 5.3/100,000 among males and 4.1/100,000 among females $(3,4)$. Primary brain tumors are a highly heterogeneous group of tumors that are still not fully understood in terms of underlying pathological mechanism. The effect of genes on the development of brain tumors is still poorly understood. However, understanding the genetic risk factors associated with a given cancer is important for selecting treatment $(5,6)$. It has been previously reported that reactive oxygen species (ROS) serve an important role in tumor development $(7,8)$. ROS may arise from intrinsic factors including mitochondria, peroxisomes and inflammatory cell activation, and contact with extrinsic factors including environmental agents, pharmaceuticals and industrial chemicals $(9,10)$. ROS cause oxidative stress, and are typically counterbalanced by antioxidant defenses of the cell (9). Oxidative stress may cause DNA, protein and/or lipid damage, leading to an increased chance of chromosome instability, genetic mutation and/or modulation of cell growth that may result in cancer (11). The association between brain tumors and antioxidant enzyme polymorphisms has been investigated by several studies in the literature $(12,13)$.

Superoxide dismutase 2 [SOD2, also known as manganese (Mn)SOD], as one of the major antioxidant enzymes, catalyzes the dismutation of superoxide radicals to $\mathrm{H}_{2} \mathrm{O}_{2}$ and oxygen in mitochondria, and thereby constitutes a first-line defense against ROS in mitochondria (13). Thus, it is conceivable that structural and/or functional polymorphisms of the SOD2 gene have critical impact on the maintenance of ROS levels in cells $(13,14)$. The SOD2 gene structure consists of five exons interrupted by four introns and the promoter, which control SOD2 expression (15). Several polymorphisms have been identified in distinct regions of the SOD2 gene (15). These polymorphisms have been associated with different diseases. SOD2 is encoded by the nuclear SOD2 gene located on the human chromosome 6q25 and the Ala16Val polymorphism has been identified in exon 2 of the human SOD2 gene. Ala16Val $(47 \mathrm{C}>\mathrm{T}$ or $\mathrm{rs} 4880)$ is a frequently studied SOD2 single nucleotide polymorphism (SNP) on SOD2 gene and is known to cause a conformational change $(15,16)$. As 
mentioned, the SOD2 Ala16Val polymorphism is located in the mitochondrial targeting sequence, and has been suggested to modify the peptide structure, affecting protein translocation and maturation into the mitochondrial matrix (17). This polymorphism has been associated with different pathologies including asthma (18), diabetes $(19,20)$, the aging process $(21)$, cardiomyopathy (22) and cancer (23).

To our knowledge, there has been no study of the association of SOD2 Ala16Val polymorphism with primary brain tumor susceptibility in a Turkish population. Therefore, in the present study, the aim was to investigate the association between the genetic polymorphism SOD2 Ala16Val and primary brain tumor risk in a Turkish population.

\section{Materials and methods}

Study population. In the present study, a total of 225 Turkish individuals were studied. Cases were brain tumor patients $(\mathrm{n}=105)$ who attended the Neurosurgery Department at Cumhuriyet University Hospital in Sivas (Central Anatolia, Turkey). Only the patients with newly diagnosed primary brain tumor and no previous radiotherapy or chemotherapy were included in the study. There was no sex, age or tumor type restriction. The diagnosis of brain tumor tissue removed by surgery was histologically confirmed and the tumor types were classified according to World Health Organization guidelines 2007 (24). Age and sex-matched controls were obtained from patients with no previous cancer diagnosis or radio-or chemotherapy recruited at the same hospital $(n=120)$. All study subjects agreed to participate and completed a short questionnaire including questions on occupation, tobacco use and family history of cancer (Table I). The local Sivas Cumhuriyet University Ethics Committee (Sivas, Turkey) on human research approved the study (approval no. 2003/304). Patients and controls were informed on the study and provided written informed consent.

DNA isolation. Peripheral blood samples ( $2 \mathrm{ml})$ were collected into citrate $(0.109 \mathrm{M})$-containing (BD Vacutainer; BD Biosciences, San Jose, CA, USA) tubes from all subjects. DNA was immediately extracted from whole blood by a salting out procedure as described previously (25).

Genotyping. The distribution of the SOD2 rs4880 polymorphism was examined using a polymerase chain reaction (PCR)-restriction fragment length polymorphism method. For amplification of the rs 4880 polymorphism, the forward primer 5'-ACCAGCAGGCAGCTGGCGCCGG-3' and reverse primer 5'-GCGTTGATGTGAGGTTCCAC-3' were used. The PCR reactions contained $0.75 \mu \mathrm{l}(25 \mathrm{pmol} / \mu \mathrm{l})$ of each primer, $2 \mu 1 \mathrm{dNTPs}(1 \mathrm{mmol} / \mathrm{l}), 1.5 \mu 1$ of $25 \mathrm{mmol} / 1 \mathrm{MgCI}_{2}$, 1.5 units of Taq DNA polymerase (5 U/ $\mu 1$ Fermentas; Thermo Scientific, Inc., Pittsburgh, PA, USA) and $16.2 \mu 1$ sterile deionized water. DNA (50-100 ng) was added to a total volume of $50 \mu \mathrm{l}$. The PCR program was initial denaturation at $95^{\circ} \mathrm{C}$ for $5 \mathrm{~min}$ followed by 35 cycles of $95^{\circ} \mathrm{C}$ for $1 \mathrm{~min}, 61^{\circ} \mathrm{C}$ for $1 \mathrm{~min}$ (annealing) and $72^{\circ} \mathrm{C}$ for $2 \mathrm{~min}$ (extension). The reaction was completed by a final extension cycle at $72^{\circ} \mathrm{C}$ for $7 \mathrm{~min}$. Amplified product was digested overnight with $P d i$ I restriction enzyme (ER1521, 200 U; Fermentas; Thermo Scientific, Inc.)
Table I. Demographics and medical history of cancer patients and controls.

\begin{tabular}{lcc}
\hline Controls & Cancer & patients \\
\hline Sample size & 120 & 105 \\
Sex & & \\
Male & $70(58.3)$ & $61(58.1)$ \\
Female & $50(41.7)$ & $44(41.9)$ \\
Age, years & & \\
Range & $14-80$ & $10-82$ \\
Mean \pm SD & $54.41 \pm 5.76$ & $51.41 \pm 16.20$ \\
Males & $55.34 \pm 5.76$ & $52.20 \pm 15.85$ \\
Females & $53.12 \pm 7.16$ & $50.32 \pm 16.79$ \\
Smoking history & & \\
Smoker & $39(32.5)$ & $40(38.1)$ \\
Non-smoker & $81(67.5)$ & $65(61.9)$ \\
P-value & 0.860 & \\
$\chi^{2}$ & 0.352 & \\
OR $\left(95 \%\right.$ CI) ${ }^{\mathrm{a}}$ & $0.77(0.44-1.33)$ & \\
Family history of cancer & & \\
Yes & $23(19.2)$ & $17(16.2)$ \\
No & $97(80.8)$ & $88(83.8)$ \\
P-value & 0.560 & \\
$\chi^{2}$ & 0.340 & \\
OR $(95 \%$ CI) & \\
\hline
\end{tabular}

Data are presented as frequency $(\%)$ or as indicated. ${ }^{\mathrm{a} O R}$ adjusted for age and family history of cancer; ${ }^{\mathrm{b}} \mathrm{OR}$ adjusted for age and smoking. $\mathrm{OR}$, odds ratio; $\mathrm{CI}$, confidence interval; $\mathrm{SD}$, standard deviation.

at $37^{\circ} \mathrm{C}$ and electrophoresed on $3 \%$ agarose gel and stained with ethidium bromide. Genotypes were determined for the polymorphism as TT (107 bp), CT (107, 89 and $18 \mathrm{bp})$ and CC (89 and 18 bp) (26).

Statistical analysis. All statistical analyses were performed using SPSS version 13.0.1 (SPSS, Inc., Chicago, IL, USA). Genotype-associated odds ratios, their corresponding 95\% confidence intervals and associated $P$ values were estimated via unconditional logistic regression. Differences in the distributions of demographic characteristics between the cases and control subjects were evaluated using a Student's t-test. $\chi^{2}$ or Fisher's exact test (two-sided) to compare the sex distribution. To determine the association between the genotypes and alleles in relation to the controls and the deviation of the genotype distribution, Hardy-Weinberg equilibrium was employed. Pearson's $\chi^{2}$ test was used to determine whether there were any significant differences in allele and genotype frequencies between patients and control subjects. Logistic regression procedures were performed to assess the interaction between age, sex and all genotypes. The association between the SOD2 Ala16Val polymorphism and primary brain tumors in five inheritance genetic models (codominant, dominant, recessive, overdominant and additive) was assessed. In addition, the recessive or dominant effect of the $S O D 2$ genotype on risk 
Table II. Genotype and allele frequencies in the primary brain tumor and the healthy control groups and association of SOD2 gene rs4880 polymorphism with the risk of primary brain tumor susceptibility according to different models of inheritance.

\begin{tabular}{|c|c|c|c|c|c|}
\hline & \multicolumn{2}{|c|}{ Group, n (\%) } & \multirow[b]{2}{*}{ OR $(95 \% \mathrm{CI})$} & \multirow[b]{2}{*}{$\chi^{2}$} & \multirow[b]{2}{*}{ P-value } \\
\hline & Controls $(n=120)$ & Cancer patients $(\mathrm{n}=105)$ & & & \\
\hline \multicolumn{6}{|c|}{ SOD2 rs4880 } \\
\hline $\mathrm{C}$ allele & $113(47.1)$ & $98(46.7)$ & 1.00 (reference) & & \\
\hline $\mathrm{T}$ allele & 127 (52.9) & $112(53.3)$ & $1.02(0.69-1.50)$ & 1.01 & 0.929 \\
\hline \multicolumn{6}{|c|}{ Codominant } \\
\hline $\mathrm{CC}$ & $29(24.2)$ & $25(23.8)$ & 1.00 (reference) & & \\
\hline $\mathrm{CT}$ & $55(45.8)$ & $48(45.7)$ & $1.01(0.50-2.07)$ & 0.01 & 0.970 \\
\hline TT & $36(30.0)$ & $32(30.5)$ & $1.03(0.47-2.25)$ & 0.01 & 0.933 \\
\hline \multicolumn{6}{|l|}{ Dominant } \\
\hline $\mathrm{CC}$ & $29(24.2)$ & $25(23.8)$ & 1.00 (reference) & & \\
\hline $\mathrm{CT}+\mathrm{TT}$ & $91(75.8)$ & $80(76.2)$ & $1.02(0.53-1.97)$ & 0.01 & 0.978 \\
\hline \multicolumn{6}{|l|}{ Recessive } \\
\hline $\mathrm{CC}+\mathrm{CT}$ & $84(70.0)$ & $73(69.5)$ & 1.00 (reference) & & \\
\hline TT & $36(30.0)$ & $32(30.5)$ & $0.96(0.52-1.75)$ & 0.02 & 0.880 \\
\hline \multicolumn{6}{|c|}{ Overdominant } \\
\hline $\mathrm{CC}+\mathrm{TT}$ & $65(54.2)$ & $57(54.3)$ & 1.00 (reference) & & \\
\hline $\mathrm{CT}$ & $55(45.8)$ & $48(45.7)$ & $1.00(0.57-1.74)$ & 0.01 & 0.986 \\
\hline
\end{tabular}

SOD2, superoxide dismutase 2; OR, odds ratio; CI, confidence interval.

was estimated, and statistical analysis was performed on the relative risk of the $\mathrm{CC}$ genotype against the $\mathrm{CT}+\mathrm{TT}$ genotype (Dominant), the $\mathrm{CC}+\mathrm{CT}$ genotype against the TT genotype (recessive) or the $\mathrm{CC}+\mathrm{TT}$ genotype against the $\mathrm{CT}$ genotype (overdominant).

\section{Results}

Demographics and medical history. The demographic characteristics of the study population are listed in Table I. The mean ages of the patients and controls were $51.41 \pm 16.20$ and $54.41 \pm 5.76$ years, respectively. The percentages of males and females in the case group were $58 \%(61 / 105)$ and $42 \%$ (44/105), respectively. The mean ages of the men and women patients were similar $(52.20 \pm 15.85$ for men and $50.32 \pm 16.79$ for women). Although family history of cancer was less prevalent in the cases $(16 \%)$ than controls (19\%), no statistically significant association was determined in the cases compared with the controls $\left(\mathrm{OR}=0.81,95 \% \mathrm{CI}=0.39-1.71, \chi^{2}=0.340, \mathrm{P}=0.560\right)$. No statistically significant difference was observed between controls $(32,5 \%)$ and cases $(38.1 \%)$ regarding smoking status $\left(\mathrm{OR}=0.77,95 \% \mathrm{CI}=0.44-1.33, \chi^{2}=0.352, \mathrm{P}=0.860\right.$; Table I $)$.

Genotype and allele frequencies. All genotypes and alleles in the controls and cases were in Hardy-Weinberg equilibrium $(\mathrm{P}>0.05)$. The frequencies of the TT, CT and CC genotypes were determined to be 30.0 vs. $30.5 \%, 45.8$ vs. $45.7 \%$ and 24.2 vs. $23.8 \%$ in the controls vs. cases, respectively $\left(\chi^{2}=0.01, \mathrm{P}=0.933 ; \chi^{2}=0.01, \mathrm{P}=0.970\right.$. The frequencies of $\mathrm{C}$ and $\mathrm{T}$ alleles were determined to be 47.1 vs. $46.7 \%$ and 52.9
Table III. ORs for the association of SOD2 gene rs4880 polymorphism with primary brain tumor incidence.

\begin{tabular}{lcc}
\hline & \multicolumn{2}{c}{ Group, $\mathrm{n}(\%)$} \\
\cline { 2 - 3 } Genotype & $\begin{array}{c}\text { Cancer patients } \\
(\mathrm{n}=105)\end{array}$ & $\begin{array}{c}\text { Controls } \\
(\mathrm{n}=120)\end{array}$ \\
\hline $\mathrm{CC}$ & $25(23.8)$ & $29(24.2)$ \\
$\mathrm{CT}+\mathrm{TT}$ & $80(76.2)$ & $91(75.8)$ \\
$\chi^{2}$ & \multicolumn{2}{c}{0.01} \\
P-value & $1.02(0.53-1.97)$ \\
Unadjusted OR $(95 \% \mathrm{CI})$ & $1.04(0.54-2.02)$ \\
Adjusted OR $(95 \% \mathrm{CI})^{\mathrm{a}}$ & \\
\hline
\end{tabular}

a OR adjusted for sex, age, smoking and family history of cancer. SOD2, superoxide dismutase 2; OR, odds ratio; CI, confidence interval.

vs. $53.3 \%$, respectively, in the controls vs. cases (Table II). The analysis of the polymorphism located at SOD2 chromosome 6 (6q25) (16) in the controls demonstrated TT (107 bp), CT (107, 89 and $18 \mathrm{bp}$ ), CC (89 and $18 \mathrm{bp}$ ) genotypes.

For the SOD2 Ala16Val polymorphism, statistically significant associations were not identified in allele frequency (C vs. T: $\mathrm{OR}=1.02$, 95\% CI=0.69-1.50, $\mathrm{P}=0.929)$, codominant (CC vs. CT: $\mathrm{OR}=1.01,95 \% \mathrm{CI}=0.50-2.07, \mathrm{P}=0.970 ; \mathrm{CC}$ vs. TT: $\mathrm{OR}=1.03,95 \% \mathrm{CI}=0.47-2.25, \mathrm{P}=0.933)$, dominant $(\mathrm{CC}$ vs. $\mathrm{CT}+\mathrm{TT}$ : $\mathrm{OR}=1.02,95 \% \mathrm{CI}=0.53-1.97, \mathrm{P}=0.978)$, recessive 
Table IV. Association between SOD2 gene rs4880 variants and histological type of brain tumor.

Histological type of brain tumor $(n=105)$

\begin{tabular}{|c|c|c|c|c|c|}
\hline Genotype & Controls & Meningioma & Astrocytoma & Hypophysis adenoma & Others \\
\hline $\mathrm{n}(\%)$ & $120(100.0)$ & $27(25.7)$ & $43(41.0)$ & $14(13.3)$ & $21(20.0)$ \\
\hline $\mathrm{CC}$ & $29(24.2)$ & $5(18.5)$ & $10(23.3)$ & $5(35.7)$ & $6(28.6)$ \\
\hline $\mathrm{CT}+\mathrm{TT}$ & $91(75.8)$ & $22(81.5)$ & $33(76.7)$ & $9(64.3)$ & $15(71.4)$ \\
\hline$\chi^{2}$ & - & 0.40 & 0.01 & 0.88 & 0.19 \\
\hline P-value & - & $0.529^{\mathrm{a}}$ & 0.941 & $0.261^{\mathrm{a}}$ & 0.666 \\
\hline OR $(95 \% \mathrm{CI})$ & - & $1.40(0.45-4.66)$ & $1.05(0.43-2.60)$ & $0.57(0.16-2.16)$ & $0.80(0.26-2.55)$ \\
\hline
\end{tabular}

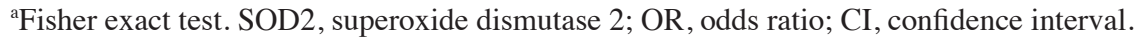

(CC+CT vs. TT: $\mathrm{OR}=0.96,95 \% \mathrm{CI}=0.52-1.75, \mathrm{P}=0.880)$ or overdominant (CC+TT vs. CT: $\mathrm{OR}=1.00,95 \% \mathrm{CI}=0.57-1.74$, $\mathrm{P}=0.986$ ) inheritance models (Table II). The SOD2 polymorphism genotype distributions in controls and cases are given in Table II.

Furthermore, there was no significant association between SOD2 rs4880 genotype and brain tumor incidence. Distribution of the SOD2 CC genotype was $23.8 \%$ in cases and 24.2\% in controls (adjusted $\mathrm{OR}=1.04,95 \% \mathrm{CI}=0.54-2.02$, $\mathrm{P}=0.978$; Table III).

Histological type of brain tumor. To evaluate the association between the polymorphism of SOD2 and the specific type of brain tumor, the patients were subdivided according to the histopathological type of the brain tumor. The most prevalent tumor types were meningioma (25.7\%), astrocytoma (41.0\%) and hypophysis adenoma (13,3\%). Others $(20.0 \%)$ included pituitary adenoma, medulloblastoma, colloid cyst, craniopharyngioma and acoustic neuroma. There was no statistically significant association of any of the tumor types with the polymorphism of the SOD2 (Table IV).

\section{Discussion}

Brain and other central nervous system tumors are a widespread public health problem, being the cause of significant mortality worldwide each year. Primary brain tumors are one of the subgroups of central nervous system tumors and the mechanism underlying their formation remains unknown. This is due to the highly heterogeneous nature of primary brain tumors; histopathological identification of tumor type and molecular epidemiology studies will be helpful in overcoming these difficulties (27-30).

Worldwide, the incidence of primary brain tumors is higher in males; however, the incidence of meningioma, histopathological types of primary brain tumor, is reported to be higher in women (31). According to the 2017 statistics of the American Cancer Society, $56.5 \%$ of all patients with primary brain tumor were men, and $43.5 \%$ were women (1). The gender distribution of patients in the present study (male: female, \%) was 58:42, and thus was consistent with previously reported incidence. The incidence, mortality and survival rates associated with brain tumors are determined by histopathological tumor type, age, gender and race. Additional risk factors include hereditary factors, alterations in expression levels of cancer-related genes, exposure to ionizing/nonionizing radiation and industrial chemicals, diet, smoking, alcohol, and occupation (26). In the present study, 120 healthy control subjects and 105 patients with primary brain tumor were compared with respect to smoking status and family history of cancer. The groups did not show significant differences with respect to smoking status $(\mathrm{P}=0.352)$ and family history of cancer $(\mathrm{P}=0.560)$.

Single nucleotide polymorphisms may be used as a tool for investigating genetic variations and disease susceptibility. A number of polymorphisms in the SOD2 gene have been documented, with polymorphism in the mitochondrial targeting sequence (rs $4880 \mathrm{C} / \mathrm{T}$ ) has been demonstrated to have functional significance (17). In particular, the $\mathrm{T}$ allele of the rs4880 C/T polymorphism in the SOD2 gene has been reported to decrease the efficiency of SOD2 protein (MnSOD) against oxidative stress $(32,33)$, which is supported by the observation that the T-variant decreases formation of the active MnSOD protein in the mitochondrial matrix (17). The association between SOD2 Ala16Val polymorphism and cancer has been investigated extensively. The Val allele and $\mathrm{Val} / \mathrm{Val}$ genotype has been associated with an increased risk of lung (34) and bladder (35) cancers, whereas the Ala allele has been associated with an increased risk of breast $(23,36)$, prostate $(37,38)$ and ovarian (39) cancers. Rosenblum et al suggested that the Ala16Val polymorphism affects the secondary structure of the protein and may alter the transfer of the enzyme into the mitochondria and its localization (40). Wang et al identified an association between Ala16Val polymorphism and lung cancer in Caucasians, and determined that $\mathrm{Val} / \mathrm{Val}$ was more common in patients with lung cancer, whereas Ala/Ala was more common in control subjects. Comparisons between carriers of Ala/Ala, Ala/Val and Val/Val revealed that Ala/Val and Val/Val were associated with a significantly higher risk (34). Zejnilovic et al investigated the association between Ala16Val polymorphism and lung cancer in a Turkish population, and identified that the frequency of the Val/Val was higher in patients compared with in control subjects (26). Meanwhile, Liu et al (41) identified that the TT genotype was associated with a significantly higher risk of oral squamous cell carcinoma $(P=0.037)$, and further analysis on genotype dominance indicated a 
significant association between the dominant genotype (TT) and oral squamous cell carcinoma $(\mathrm{P}=0.013)$. In the current study, the frequency of the CC genotype was $24.2 \%$, of the CT genotype was $45.8 \%$, and of the TT genotype was $30.0 \%$ in controls. When considering frequencies in patients $(23.8$, 45.7 and $30.5 \%$, respectively), there were no significant associations between these genotypes and the incidence of primary brain tumor $(\mathrm{P}>0.05)$. Similar to Liu et al (41), the genotypes were also evaluated in terms of associations of codominant, dominant, recessive and overdominant models with tumor risk. However, a significant association between the incidence of primary brain tumor and these genotypes was not determined $(\mathrm{P}>0.05)$.

Histopathological classification of primary brain tumors demonstrated that astrocytoma was the most common tumor $(41.0 \%)$. Meningioma was the second most common tumor type $(25.7 \%)$, and other common tumors included medulloblastoma, colloid cysts, craniopharyngioma, acoustic neuroma (collectively $20.0 \%$ ) and pituitary adenoma (13.3\%). Rajaraman et al (12) reported that glioma (astrocytoma) had the highest incidence $(64.1 \%$; $n=362)$, followed by meningioma $(23.7 \% \mathrm{n}=134)$ and acoustic neuroma $(12.2 \% ; n=69)$ in the United States. The reported frequency of meningioma by Rajaraman et al (12) is consistent with the present study, while the previously observed frequency of astrocytoma is higher. Similar to the present study, Rajaraman et al (12) identified no significant association between SOD2 Ala16Val polymorphism and primary brain tumors $(\mathrm{P}>0.05)$. Contrary to these findings, Zhao et al (42) determined a significant association between SOD2 Ala16Val polymorphism and glioma $(\mathrm{P}<0.05)$. The association between SOD2 Ala16Val polymorphism and primary brain tumors requires further investigation using a larger number of cases and controls.

In conclusion, the present data suggested that SOD2 Ala16Val polymorphism was not a risk factor for primary brain tumor in a Turkish population. To the best of our knowledge, the current study is the first on a Turkish population, and the second on SOD2 Ala16Val polymorphism and primary brain tumor association following investigation by Rajaraman et al (12). Further research on polymorphisms associated with SOD2 isoforms (SOD1, SOD3) and other antioxidant enzymes in a larger study population is now required to achieve more comprehensive and accurate data.

\section{Acknowledgements}

The authors would like to thank Dr Ziynet Çınar (Sivas Cumhuriyet University, Medical School, Department of Biostatistics, Sivas, Turkey) for statistical analysis.

\section{Funding}

The current study was funded by Sivas Cumhuriyet University (Sivas, Turkey) via research grants (grant no. CÜBAP T-403) provided to the project.

\section{Availability of data and materials}

The datasets used and/or analyzed during the current study are available from the corresponding author on reasonable request.

\section{Authors' contributions}

MG diagnosed and treated the patients. AT and YS conducted laboratory test. AT and HP collected the data and analyzed the results. AT and YS wrote the manuscript. All authors read and approved the final manuscript.

\section{Ethics approval and consent to participate}

This study was approved by local Sivas Cumhuriyet University Ethics Committee (approval no. 2003/304; Sivas, Turkey).

\section{Patient consent for publication}

Not applicable.

\section{Competing interests}

The authors declare that they have no competing interests.

\section{References}

1. Siegel RL, Miller KD and Jemal A: Cancer statistics, 2018. CA Cancer J Clin 68: 7-30, 2018.

2. Ricard D, Idbaih A, Ducray F, Lahutte M, Hoang-Xuan K and Delattre JY: Primary brain tumours in adults. Lancet 379: 1984-1996, 2012.

3. Turkish Cancer Statistics Database: (2015). Department of Cancer Turkish Ministry of Health, 2018. www.kanser.gov.tr

4. Republic of Turkey, Ministry of Health, General Directorate of Public Health: Turkish Cancer Statistics 2015. http://www.hsgm. gov.tr.

5. Pinarbasi H, Silig Y and Gurelik M: Genetic polymorphisms of GSTs and their association with primary brain tumor incidence. Cancer Genet Cytogenet 156: 144-149, 2005.

6. Rajaraman P, Melin BS, Wang Z, McKean-Cowdin R, Michaud DS, Wang SS, Bondy M, Houlston R, Jenkins RB, Wrensch M, et al: Genome-wide association study of glioma and meta-analysis. Hum Genet 131: 1877-1888, 2012.

7. Ishikawa K, Takenaga K, Akimoto M, Koshikawa N, Yamaguchi A, Imanishi H, Nakada K, Honma Y and Hayashi J: ROS-generating mitochondrial DNA mutations can regulate tumor cell metastasis. Science 320: 661-664, 2008.

8. Kumar B, Koul S, Khandrika L, Meacham RB and Koul HK: Oxidative stress is inherent in prostate cancer cells and mediates aggressive phenotype. J Urol 179 (4s): 192-193, 2008.

9. Klaunig JE and Kamendulis LM: The role of oxidative stress in carcinogenesis. Annu Rev Pharmacol Toxicol 44: 239-267, 2004.

10. Tudek B, Winczura A, Janik J, Siomek A, Foksinski M and Oliński R: Involvement of oxidatively damaged DNA and repair in cancer development and aging. Am J Transl Res 2: 254-284, 2010.

11. Klaunig JE, Kamendulis LM and Hocevar BA: Oxidative stress and oxidative damage in carcinogenesis. Toxicol Pathol 38: 96-109, 2010

12. Rajaraman P, Hutchinson A, Rothman N, Black PM, Fine HA, Loeffler JS, Selker RG, Shapiro WR, Linet MS and Inskip PD: Oxidative response gene polymorphisms and risk of adult brain tumors. Neuro-oncol 10: 709-715, 2008.

13. Bag A and Bag N: Target sequence polymorphism of human manganese superoxide dismutase gene and its association with cancer risk: A review. Cancer Epidemiol Biomarkers Prev 17: 3298-3305, 2008.

14. Tamimi RM, Hankinson SE, Spiegelman D, Colditz GA and Hunter DJ: Manganese superoxide dismutase polymorphism, plasma antioxidants, cigarette smoking, and risk of breast cancer. Cancer Epidemiol Biomarkers Prev 13: 989-996, 2004.

15. Wan XS, Devalaraja MN and St Clair DK: Molecular structure and organization of the human manganese superoxide dismutase gene. DNA Cell Biol 13: 1127-1136, 1994.

16. Pourvali K, Abbasi M and Mottaghi A: Role of superoxide dismutase 2 gene Ala16Val polymorphism and total antioxidant capacity in diabetes and its complications. Avicenna J Med Biotechnol 8: 48-56, 2016. 
17. Sutton A, Khoury H, Prip-Buus C, Cepanec C, Pessayre D and Degoul F: The Ala16Val genetic dimorphism modulates the import of human manganese superoxide dismutase into rat liver mitochondria. Pharmacogenetics 13: 145-157, 2003.

18. Kinnula VL, Lehtonen S, Koistinen P, Kakko S, Savolainen M, Kere J, Ollikainen V and Laitinen T: Two functional variants of the superoxide dismutase genes in Finnish families with asthma. Thorax 59: 116-119, 2004.

19. Lee SJ, Choi MG, Kim DS and Kim TW: Manganese superoxide dismutase gene polymorphism (V16A) is associated with stages of albuminuria in Korean type 2 diabetic patients. Metabolism 55: 1-7, 2006.

20. Zotova EV, Chistiakov DA, Savost'ianov KV, Bursa TR, Galeev IV, Strokov IA and Nosikov VV: Association of the SOD2 Ala(-9)Val and SOD3 Arg213Gly polymorphisms with diabetic polyneuropathy in patients with diabetes mellitus type 1. Mol Biol (Mosk) 37: 404-408, 2003 (In Russian).

21. Taufer M, Peres A, de Andrade VM, de Oliveira G, Sá G, do Canto ME, dos Santos AR, Bauer ME and da Cruz IB: Is the Val16Ala manganese superoxide dismutase polymorphism associated with the aging process? J Gerontol A Biol Sci Med Sci 60: 432-438, 2005.

22. Hiroi S, Harada H, Nishi H, Satoh M, Nagai R and Kimura A: Polymorphisms in the SOD2 and HLA-DRB1 genes are associated with nonfamilial idiopathic dilated cardiomyopathy in Japanese. Biochem Biophys Res Commun 261: 332-339, 1999.

23. Mitrunen K, Sillanpää P, Kataja V, Eskelinen M, Kosma VM, Benhamou S, Uusitupa M and Hirvonen A: Association between manganese superoxide dismutase (MnSOD) gene polymorphism and breast cancer risk. Carcinogenesis 22: 827-829, 2001.

24. Louis DN, Ohgaki H, Wiestler OD, Cavenee WK, Burger PC, Jouvet A, Scheithauer BW and Kleihues P: The 2007 WHO classification of tumours of the central nervous system. Acta Neuropathol 114: 97-109, 2007

25. Tas A, Atabey M, Caglayan G, Bostanci ME, Sahin Bolukbasi S, Topcu $\mathrm{O}$ and Silig Y: Investigation of the association between the MDM2 T309G polymorphism and gastric cancer. Biomed Rep 7: 469-473, 2017

26. Zejnilovic J, Akev N, Yilmaz H and Isbir T: Association between manganese superoxide dismutase polymorphism and risk of lung cancer. Cancer Genet Cytogenet 189: 1-4, 2009.

27. Fisher JL, Schwartzbaum JA, Wrensch M and Wiemels JL: Epidemiology of brain tumors. Neurol Clin 25: 867-890, vii, 2007.

28. De Roos AJ, Rothman N, Inskip PD, Linet MS, Shapiro WR, Selker RG, Fine HA, Black PM, Pittman GS and Bell DA: Genetic polymorphisms in GSTM1, -P1, -T1, and CYP2E1 and the risk of adult brain tumors. Cancer Epidemiol Biomarkers Prev 12: 14-22, 2003.

29. Gu J, Liu Y, Kyritsis AP and Bondy ML: Molecular epidemiology of primary brain tumors. Neurotherapeutics 6: 427-435, 2009.

30. American Brain Tumor Association: Brain Tumor Primer - A Comprehensive Introduction to Brain Tumor. 9th edition. ABT Press, 2012.
31. Sathornsumetee S and Rich JN: New approaches to primary brain tumor treatment. Anticancer Drugs 17: 1003-1016, 2006.

32. Sun GG, Wang YD, Lu YF and Hu WN: Different association of manganese superoxide dismutase gene polymorphisms with risk of prostate, esophageal, and lung cancers: Evidence from a meta-analysis of 20,025 subjects. Asian Pac J Cancer Prev 14: 1937-1943, 2013

33. Shimoda-Matsubayashi S, Matsumine H, Kobayashi $T$, Nakagawa-Hattori Y, Shimizu Y and Mizuno Y: Structural dimorphism in the mitochondrial targeting sequence in the human manganese superoxide dismutase gene. A predictive evidence for conformational change to influence mitochondrial transport and a study of allelic association in Parkinson's disease. Biochem Biophys Res Commun 226: 561-565, 1996.

34. Wang LI, Miller DP, Sai Y, Liu G, Su L, Wain JC, Lynch TJ and Christiani DC: Manganese superoxide dismutase alanine-to-valine polymorphism at codon 16 and lung cancer risk. J Natl Cancer Inst 93: 1818-1821, 2001.

35. Hung RJ, Boffetta P, Brennan P, Malaveille C, Gelatti U,Placidi D, Carta A, Hautefeuille A and Porru S: Genetic polymorphisms of MPO, COMT, MnSOD, NQO1, interactions with environmental exposures and bladder cancer risk. Carcinogenesis 25: 973-978, 2004.

36. Ambrosone CB, Freudenheim JL, Thompson PA, Bowman E, Vena JE, Marshall JR, Graham S, Laughlin R, Nemoto T and Shields PG: Manganese superoxide dismutase (MnSOD) genetic polymorphisms, dietary antioxidants, and risk of breast cancer. Cancer Res 59: 602-606, 1999.

37. Ergen HA, Narter F, Timirci O and Isbir T: Effects of manganase superoxide dismutase Ala-9Val polymorphism on prostate cancer: A case-control study. Anticancer Res 27: 1227-1230, 2007.

38. Woodson K, Tangrea JA, Lehman TA, Modali R, Taylor KM, Snyder K, Taylor PR, Virtamo J and Albanes D: Manganese superoxide dismutase (MnSOD) polymorphism, $\alpha$-tocopherol supplementation and prostate cancer risk in the $\alpha$-tocopherol, beta-carotene cancer prevention study (Finland). Cancer Causes Control 14: 513-518, 2003.

39. Olson SH, Carlson MD, Ostrer H, Harlap S, Stone A, Winters M and Ambrosone CB: Genetic variants in SOD2, MPO, and NQO1, and risk of ovarian cancer. Gynecol Oncol 93: 615-620, 2004.

40. Rosenblum JS, Gilula NB and Lerner RA: On signal sequence polymorphisms and diseases of distribution. Proc Natl Acad Sci USA 93: 4471-4473, 1996.

41. Liu Y, Zha L, Li B, Zhang L, Yu T and Li L: Correlation between superoxide dismutase 1 and 2 polymorphisms and susceptibility to oral squamous cell carcinoma. Exp Ther Med 7: 171-178, 2014.

42. Zhao P, Zhao L, Zou P, Lu A, Liu N, Yan W, Kang C, Fu Z, You Y and Jiang T: Genetic oxidative stress variants and glioma risk in a Chinese population: A hospital-based case-control study. BMC Cancer 12: 617, 2012. 